\title{
ALENDRONATE-INDUCED RESPIRATORY DISTRESS
}

\author{
PRAVALIKA M ${ }^{1 *}$, SRIVANI V ${ }^{1}$, SAGAR PAMU ${ }^{2,3}$
}

${ }^{1}$ Department of Pharmaceutical Analysis, Geethanjali College of Pharmacy, Hyderabad, Telangana, India. ${ }^{2}$ Department of Pharmacy Practice, Guru Nanak Institutions Technical Campus - School of Pharmacy, Ibrahimpatnam, Ranga Reddy, Hyderabad, Telangana, India.

${ }^{3}$ Department of Pharmacy Practice, Lovely Professional University, Phagwara, Punjab, India. Email: pravalikamethuku@gmail.com

Received: 08 April 2020, Revised and Accepted: 06 May 2020

\section{ABSTRACT}

Respiratory distress is a rare adverse effect of alendronate that is typically associated with severe dyspnoea and wheezing and typically requires hospitalization. The patient with a history of dyspnoea and wheezing during the strenuous workload was treated promptly with alendronate for newly diagnosed osteoporosis. After 2 days, respiratory distress complications were restarted and we accurately reported the patient with basophilia, elevated immunoglobulin $\mathrm{E}$ (with a blood test), and allergic bronchopulmonary aspergillosis (with computed tomography scan image). The prospective patient was adequately understood as alendronate-induced respiratory distress with an unfortunate rechallenge method. Although there is no direct causal relationship from this adverse case report, the possible mechanism has discussed typically based on peer-reviewed literature.

Keywords: Alendronate, Respiratory distress, Dyspnoea, Wheezing, Allergic bronchopulmonary aspergillosis, Basophilia, Elevated immunoglobulin E.

(c) 2020 The Authors. Published by Innovare Academic Sciences Pvt Ltd. This is an open access article under the CC BY license (http://creativecommons. org/licenses/by/4. 0/) DOI: http://dx.doi.org/10.22159/ajpcr.2020.v13i7.37811

\section{INTRODUCTION}

Alendronate is a specific osteoclast inhibitor used in the preferential treatment of osteoporosis and has a place with the class of bisphosphonates. It works by forestalling the resorption of bone. Alendronate is not indicated for use in pediatric populations [1]. Alendronic acid binds to bone hydroxyapatite in which endocytic vesicles are fermented, promptly releasing alendronic acid to the cytosol of osteoclasts, where they instigate apoptosis [2]. Adverse impacts of alendronate, for example, dyspepsia to esophageal stricture, muscle torment, influenza-like disorder, and vertigo, have been accurately accounted [3]. Liquor, cocaine, amphetamines, sedatives, and benzodiazepines are the most normally manhandled drugs that may instigate intense respiratory distress [4], yet alendronate is the medication which is recently revealed as causing respiratory distress, for example, dyspnea and wheezing.

\section{CASE REPORT}

A 50 year-elderly male person was conceded in casualty with dyspnea and wheezing. He works laboriously in the coal mine shafts and had a social history of smoking for 5 years. His clinical history was seen with troubled breath during strenuous physical action from the most recent 2 years and had been well controlled with inhaled salbutamol. He is not an asthmatic patient prior, however, feels labored breath during physical pressure. He likewise diminished his strenuous workload in coal mine shafts and denied having troubled breath from the past 1 year and quitted salbutamol inhalation. The patient was diagnosed as osteoporosis just 10 days to his prior admission and started alendronate $10 \mathrm{mg}$ po every day. Following 2 days, the patient was admitted in casualty with wheezing and dyspnea. His vital signs were respiratory rate -31 breaths/min, oxygen saturation - $94 \%$, pulse -110 beats/min, circulatory strain - $130 / 70 \mathrm{~mm} \mathrm{Hg}$, and temperature $-37^{\circ} \mathrm{C}$. His breath sounds were diminished and expiratory phase prolonged. The cardiovascular assessment was noteworthy for tachycardia. His physical examination was normal. The patient's chest radiography and electrocardiogram were normal. Consequences of his renal and liver capacity tests and urinalysis were also normal. Blood picture demonstrated normal range of hemoglobin $-14.0 \mathrm{~g} / \mathrm{dL}$, hematocrit $-45 \%$, white blood cell count -8000 cells $/ \mathrm{m}^{3}$, and platelets $-300,000 / \mathrm{m}^{3}$. He was reported with elevated levels of basophils -0.69 (reference range 0.04-0.4) and serum immunoglobulin E - $250 \mathrm{ng} / \mathrm{mL}$ (reference go 0-81 ng/mL). An infectious check C-reactive protein level, erythrocyte sedimentation rate, and microbiological exam of sputum were negative. The computed tomography (CT) scan picture reveals allergic bronchopulmonary aspergillosis and typically indicated focal varicoid bronchiectasis (Fig. 1). A factual finding of intense respiratory distress was made and supplemented with adequate oxygen. He was instantly treated with nebulized albuterol and intravenous hydrocortisone.

The likely patient improved within $24 \mathrm{~h}$ of admission and was discharged. With the suspicion of conceivable alendronate-induced respiratory complications, alendronate was stopped and the patient's past prescription was started. After the suspension of alendronate, he had no complaints for the following 3 weeks. As the patient was restarted with the symptoms of osteoporosis, he again administered the alendronate with recommendations from another doctor (who is unaware of his respiratory distress because of alendronate). After the second dose of alendronate, he again experienced dyspnea and wheezing within few hours and was admitted to the emergency department. Based on his readministered alendronate information and respiratory symptoms, he was restarted with albuterol and hydrocortisone. Within the very early hours of effective treatment, hypoxemia resolved.

\section{DISCUSSION}

This is a bizarre and uncommon case report of alendronate-induced respiratory distress. As per the Naranjo probability scale, alendronate was a reasonable justification for the patient's respiratory trouble right now [4]. Although no direct causal relationship can be drawn from this report, the relationship between the alendronate use and the beginning of the respiratory distress was promptly accepted because of alendronate, particularly with given consequences of an unfortunate rechallenge.

In the literature, there are a few published reports about alendronate that typically show a dose-dependent rise of histidine decarboxylase movement in different tissues (e.g., liver, lung, and spleen), prompting an expansion in histamine [5-7]. One of the other studies exhibits that basophils of selected patients with hypersensitive bronchopulmonary aspergillosis have marked cell hyperreactivity and patients with allergic bronchopulmonary aspergillosis had significantly more prominent histamine release to Aspergillus antigens [8]. This conversation result proposes a potential mechanism for worsening of an inflammatory reaction like respiratory distress because of histamine release [6] with 


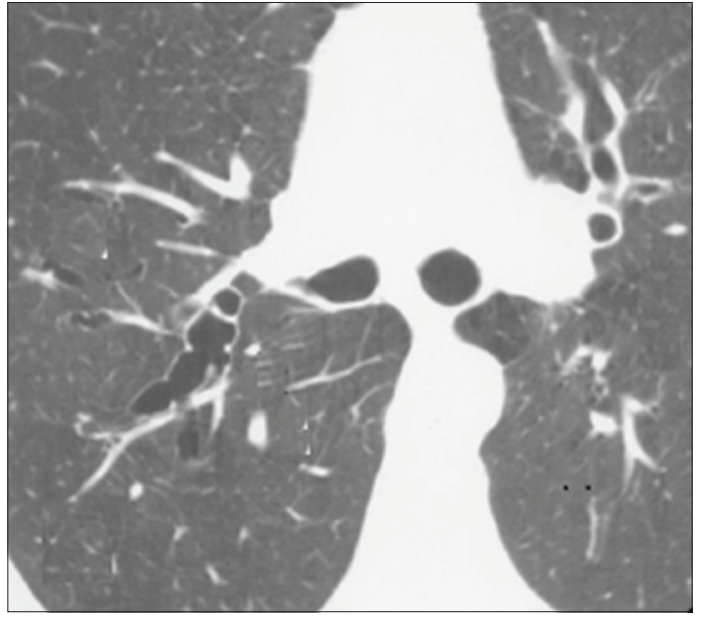

Fig. 1: Allergic bronchopulmonary aspergillosis. Thin-section computed tomography scan shows central varicoid bronchiectasis

the cause of allergic bronchopulmonary aspergillosis [8]. The patients with allergic bronchopulmonary aspergillosis were typically revealed with basophilia and raised serum immunoglobulin in a study [8] and the same was recognized in this case report.

The above literature discussion may have played a role in the patient, but no single factor was likely solely responsible for the key development of respiratory distress. Esophageal irritation can typically cause stimulation of the vagal nerve at the inferior site of the esophagus, which can also lead to bronchoconstriction [9].

\section{CONCLUSION}

This uncommon occurrence of respiratory trouble may reveal precisely insight with expanded use of alendronate. The clinical significance and possible mechanism of this rare adverse reaction are still to be understood clearly. Clinicians ought to know that alendronate can cause an assault in patients with respiratory distress.

\section{AUTHORS' CONTRIBUTIONS}

Pravalika $\mathrm{M}$ and Srivani $\mathrm{V}$ have efficiently performed the manuscript draft. Dr. Sagar Pamu has detected the ADR case report, collected from the hospital, carefully revised, and edited the drafted manuscript.

\section{CONFLICTS OF INTEREST}

No authors are undoubtedly having any conflicts of interest in regard to this article publication.

\section{AUTHORS' FUNDINC}

No funding source for this case report.

\section{REFERENCES}

1. Porras AG, Holland SD, Gertz BJ. Pharmacokinetics of alendronate. Clin Pharmacokinet 1999;36:315-28.

2. Russell RG, Watts NB, Ebetino FH, Rogers MJ. Mechanisms of action of bisphosphonates: Similarities and differences and their potential influence on clinical efficacy. Osteoporos Int 2008;19:733-59.

3. Burstein HJ, Elias AD, Rugo HS, Coleigh MA, Wolff AC, Eisenberg PD, et al. Phase II study of sunitinib malate, an oral multitargeted tyrosine kinase inhibitor, in patients with metastatic breast cancer previously treated with an anthracycline and a taxane. $\mathrm{J}$ Clin Oncol 2008;26:1810-6.

4. Naranjo CA, Busto U, Sellers EM, Sandor P, Ruiz I, Roberts EA, et al. A method of estimating the probability of adverse drug reactions. Clin Pharmacol Ther 1981;30:239-45.

5. Endo Y, Nakamura M, Kikuchi T, Shinoda H, Takedu Y, Nitta Y, et al. Aminoalkylbisphosphonates, potent inhibitors of bone resorption, induce a prolonged stimulation of histamine synthesis and increase macrophages, granulocytes, and osteoclasts in vivo. Calcif Tissue Int 1993;52:248-54

6. Funayama H, Mayanagi H, Takada H, Endo Y. Elevation of histidine decarboxylase activity in the mandible of mice by Prevotella intermedia lipopolysaccharide and its augmentation by an aminobisphosphonate. Arch Oral Biol 2000;45:787-95.

7. Deng X, Zhiqian Y, Funayama H, Shoji N, Sasano T, Iwakura Y, et al. Mutual augmentation of the induction of the histamine-forming enzyme, histidine decarboxylase, between alendronate and immunostimulants (IL-1, TNF, and LPS), and its prevention by clodronate. Toxicol Appl Pharmacol 2006;213:64-73.

8. Anthony JR, Paul AG, Jacob JP, Roy P. Hyperreactivity of mediatorreleasing cells from patients with allergic bronchopulmonary aspergillosis as evidenced by basophil histamine release. J Allergy Clin Immunol 1983;72:386-92.

9. Rolla G, Bucca C, Brussino L. Bisphosphonate-induced bronchoconstriction in aspirin-sensitive asthma. Lancet 1994;343:426-7. 